\title{
Transport Turnover with Spatial Econometric Perspective under the Energy Conservation and Emissions Reduction in China
}

\author{
Zhongzhen Yang, Wensi Wang, Hongli Bao, Lu Kong, and Bin Yu \\ Management College, Dalian Maritime University, Dalian 116026, China \\ Correspondence should be addressed to Bin Yu; ybzhyb@163.com
}

Received 4 October 2013; Revised 13 October 2013; Accepted 14 October 2013

Academic Editor: Baozhen Yao

Copyright ( 2013 Zhongzhen Yang et al. This is an open access article distributed under the Creative Commons Attribution License, which permits unrestricted use, distribution, and reproduction in any medium, provided the original work is properly cited.

\begin{abstract}
The method of spatial econometrics model is used to study the space correlation of road turnover (freight and passenger) among the 31 provinces (municipalities and autonomous regions) in China. Since some factors (such as the level of economic development, industrial structure, and population) may impact the road turnover (freight and passenger), these indexes are used as variables to reflect the influence in this model. The data of 31 provinces (municipalities and autonomous regions) in China in 2012 is collected to analyze the method. The results show that when the characteristics of turnover in a region are analyzed, it is necessary to consider the influence of its surrounding areas in space. Different scenarios were established according to different economic growth and degree of emission reduction to analyze the influence of the reduction of road turnover in regions with high spatial cluster effect to the whole country. We also carried out how to use the space effect of road turnover to the energy saving and emission reduction in the transportation industry.
\end{abstract}

\section{Introduction}

Since the Copenhagen conference [1], energy saving and emission reduction has become a hot issue around the world. The government of China has restated its commitment to achieving a $40-45 \%$ reduction in carbon emissions per unit of GDP by 2020 compared with 2005 . With the increase of transport turnover in China, the scale of energy consumption in transportation industry increased year by year. Lots of cities attempt to solve the emission problem by improving urban public transportation [2-5]. However, the method cannot fundamentally solve the problem. The total energy consumption of transportation and related industries is 236.92 million tons of standard coal in 2009, accounting for $7.7 \%$ of the energy consumption of the whole country, just after industry and living consumption. Hence, it can be seen that if the target of carbon reduction can be achieved, transportation industry must take effective measures.

At present, many measures have been taken for the energy conservation in transportation industry all over the world, one of which is optimizing the structure of transportation.
Many papers recommended that if part of the freight and passenger carried by road is transferred to railway and waterway, the energy consumption can be cut down. Authorities want to save energy and reduce emissions through transfer of the cargoes or passengers carried by road to water. So it is necessary to clear the characteristics and influencing factors of turnover first. Most of the current researches assumed that the turnover in each region is independent, and the influences of the surrounding areas are ignored. In fact, transportation industry is transport activities among different areas. This feature determines the dependence and spillover effects of turnover on geographical space. In addition, with the speeding up of the process of regional economic integration, regional cooperation will become increasingly frequent. The process will also make the data of transport turnover show some spatial dependence. Therefore, if this objective existence of spatial dependence is ignored, it is easy to produce model bias and make the conclusion of the study lack explanatory power. This paper argues that transport turnover is not only related to the region's economic and demographic factors, but also has a spatial effect. When the 
transport structure of one region is adjusted, the interaction of the adjacent and close areas should be considered. Hence, in order to clear the influence to carbon reduction when turnover of road is decreased, studying the space correlation of transport turnover is of great significance.

In this paper, spatial econometrics model is used to find the relation between road turnover (freight and passenger) and the level of economic development, industrial structure, and population. The space correlation of the road turnover among 31 provinces (municipalities and autonomous regions) in China is also checked with the method. Different scenarios were established according to different economic growth and degree of emission reduction to analyze the influence of the reduction of road turnover in regions with high spatial cluster effect to the whole country. In order to achieve the emission reduction targets, China is bound to carry out macrocontrol. This paper provides a reference for the macrocontrol of China through analyzing the space correlation of the road turnover, and we also propose how to apply the characteristics of transport turnover to the energy conservation in the transportation industry.

\section{Literature Review}

During the past few decades, the concept of energy has received great attention from scientists, researchers, and engineers and has been applied to various industrial sectors and thermal processes. Saidur et al. [6] applied the useful energy and energy analysis models for different modes of transport in Malaysia and compared the result with a few countries. The result showed that the road subsector appeared to be the most efficient one compared to the air and marine subsectors. Jeffrey and Yanjia [7] examined trends in freight and passenger traffic to assess how growth in China's transport demand relates to growth in China's economy, as well as the energy intensity of transport. China's transport sector would likely raise world oil prices in 2020 by $1-3 \%$ in reference scenarios or by $3-10 \%$ if oil supply investment is constrained. Amekudzi et al. [8] presented a sustainability footprint framework and model that may be used in analyzing the impacts of transportation and other infrastructure systems on regional sustainable development.

Spatial econometrics is a rather recent methodological development in econometrics and has been rapidly growing as useful statistical tools for analysis of spatial dependence and spatial effect including externalities, spillovers, spatial interactions, social network effects, and peer effects in economic, demographic, political, and social studies $[9,10]$. Rey and Montouri [11] considered the question of US regional economic income convergence from a spatial econometric perspective. A spatial econometric analysis of the familiar Baumol specification reveals strong evidence of misspecification due to ignored spatial error dependence. Brasington and Hite [12] estimate the relationship between house prices and environmental disamenities using spatial statistics, confirming that nearby point-source pollutants depress house price. There have been studies on spatial econometric models both for panel data ([13-16]: among others) and for cross-sectional data $([13,17,18]$ : among others).

\section{Spatial Econometrics Model}

According to the method and principle of spatial statistics and spatial econometrics, the basic idea for spatial econometric analysis of this paper is as follows. The Moran index method of spatial statistical analysis is used to test whether the spatial dependence of road turnover (the dependent variable) exists. If it exists, the spatial econometrics model will be established to proceed with spatial econometrics estimation and test.

3.1. Spatial Correlation. When studying the characteristics of an area, we usually depend on the sample data collected from each point in the space. But in general, because of the factors such as economy and culture, regions are not completely independent. There is, spatial correlation among spatial data of each region. Spatial correlation refers to the nonrandom spatial relevance between the observed values $i$ and $j(i \neq j)$ in two regions, which can be expressed as

$$
y_{i}=f\left(y_{j}\right), \quad j=1, \ldots, n,(j \neq i) .
$$

We say that there is a spatial correlation between each two regions, but do not deny the relative independence between them. Generally, we believe that the spatial correlation between close regions is better than that of far away.

Moran derived spatial autocorrelation to study the spatial random distribution among two or higher dimension for the first time. By far, there are many methods to measure and test spatial correlation. This paper uses Moran's $I$ index method which is mainly used to test whether the variables have spatial correlation on the whole, that is, the global spatial correlation. Global Moran's I index is defined as

$$
\text { Moran's } I=\frac{\sum_{i=1}^{n} \sum_{j=1}^{n} \mathbf{W}_{i j}\left(Y_{i}-\bar{Y}\right)\left(Y_{j}-\bar{Y}\right)}{S^{2} \sum_{i=1}^{n} \sum_{j=1}^{n} \mathbf{W}_{i j}},
$$

where $S^{2}=(1 / n) \sum_{i=1}^{n}\left(Y_{i}-\bar{Y}\right)$ and $\bar{Y}=(1 / n) \sum_{i=1}^{n} Y_{i}$, $Y_{i}$ represent the observed value in region $i$ (such as freight and passenger turnover of road in this paper), $n$ is the total number of the regions (it is 31 in this paper), and $\mathbf{W}_{i j}$ is spatial weight matrix to define the adjacent relation of spatial object.

The value of global Moran's $I$ index is between -1 and 1 . If it is greater than 0 , there is a positive autocorrelation in space. And the higher the value is, the stronger the correlation is. If the value of global Moran's $I$ index is less than 0 , it means that the units do not have similar properties with their spatial adjacency. And the smaller value represents the greater difference among the units. The value of zero means that there is not any spatial correlation between various units, and they are subject to random distribution.

Through drawing Moran scatter plot which is a supplement to Moran's index, the spatial correlation in the local area can be revealed. In Moran scatter plot, the abscissa is the deviation of observed values in each area, and the ordinate is the value of spatial lag. Four different quadrants correspond to the four different types of local space link, respectively. Regions located in the first quadrant have larger observed values and their nearby areas also have larger observations. Such regions are called high-high areas and the quadrant they 
locate in is defined as HH. Regions located in the second quadrant have smaller observations, but their nearby areas have larger observations. Such regions are called low-high areas and the quadrant they locate in is defined as LH. Similarly we call the third quadrant LL and the fourth HL. HH and LL quadrants indicate positive spatial autocorrelation and aggregation of close observed values in space, while $\mathrm{LH}$ and HL quadrants indicate that the regions in them are negatively correlated with their neighborhood. The oblique line through the first and the third quadrants expresses the value of global spatial autocorrelation. By Moran scatter plot, the phenomenon of spatial differentiation and agglomeration can be further understood.

Local spatial correlation is also known as local indicators of spatial association (LISA). This paper adopts a local Moran's Index, which is defined as

$$
\text { Moran's } I=Z_{i} \sum_{j=1}^{n} \mathbf{W}_{i j} Z_{j} \quad(i \neq j),
$$

where $Z_{i}=x_{i}-\bar{x}$ and $Z_{j}=x_{j}-\bar{x}$, respectively, mean the interest margin of the observed values and average values. $x_{i}$ represents the observed value of spatial unit, and $\mathbf{W}_{i j}$ signifies spatial weight matrix. Thus, Moran's I Index can be indicated as the product of the deviation of observed values in space unit $i\left(Z_{i}\right)$ and the weighted average of deviation values observed in its adjacent space $j$.

When carried on the spatial correlation test, there are three methods to set the spatial weight matrix. One is by contiguity weight; that is, if geographic units $a$ and $b$ are adjacent, $\mathbf{W}_{i j}=1$, otherwise, $\mathbf{W}_{i j}=0$. Another is by distance weight; the upper limit of surrounding distance can be chosen autonomously according to the research content. The last is by $\mathrm{K}$-nearest neighbor spatial weights. An appropriate matrix will be selected to be used in the space model through examining the contiguity weight and distance weight in our paper.

3.2. Spatial Model. According to the related theory of spatial panel model, relationships of spatial autocorrelation are in two forms: spatial lag model (SLM) and spatial error model (SEM). In the spatial lag model, the spatial relevance of variable is reflected by the space lag of the dependent variables. Spatial lag model is mainly focused on whether the variables in a region have diffusion effect (or spillover effect).

(1) Spatial Lag Model (SLM). Model as follows:

$$
Y=\rho \times \mathbf{W}_{y}+X \beta+\varepsilon .
$$

$Y$ is explanatory variables. $X$ is the exogenous variable matrix of $n \times k$. $\rho$ is coefficient for spatial regression, which reflects the relationship among spatial units. That is to say, it is the degree of influence of the adjacent space units to one space unit (the degree of influence is vector with certain direction). $\mathbf{W}$ is spatial weight matrix of $n \times n$, and $\mathbf{W}_{y}$ is the spatially lagged dependent variables of $\mathbf{W} . \varepsilon$ is the random error vector. Parameter $\beta$ mainly reflects the influence of independent variable $X$ to dependent variable $Y . \mathbf{W}_{y}$ is an endogenous variable, reflecting how the spatial distance affects each space unit.
(2) Spatial Error Model (SEM). Model as follows:

$$
\begin{gathered}
Y=X \beta+\varepsilon, \\
\varepsilon=\lambda \times \mathbf{W} \varepsilon+\mu .
\end{gathered}
$$

$Y$ is dependent variables, and $X$ is the exogenous variable matrix of $n \times k$. W is spatial weight matrix of $n \times n$. $\varepsilon$ is the random error vector. $\mu$ is the random error vector of normal distribution. Parameter $\beta$ is the influence coefficient of independent variable $X$ to dependent variable $Y . \lambda$ is the space error coefficient of dependent variable vector.

\section{Empirical Analysis}

In this paper, the space unit is 31 provinces in China. The measurement is freight and passenger turnover of each province from 1980 to 2012. Firstly, global spatial correlation index (Moran's I) is used to test whether road turnover (freight and passenger) of each province has self-correlation in space and cluster phenomenon. Then, by local indicators of spatial association (LISA), it is further analyzed to reveal the spatial correlation of road turnover (freight and passenger) in adjacent provinces. Moreover, spatial regression is used to search the relation between the turnover of road and the level of economic development, industrial structure, and population. And this section also puts forward an approach on how to apply the characteristics of turnover to energy conservation and emissions reduction in transport industry.

\subsection{Data Collection and Process}

4.1.1. $\mathrm{TOV}_{i}$, the Freight and Passenger Turnover of Road Transportation. This paper studies the spatial relation of road turnover (freight and passenger) among 31 provinces in China. Hence, the data of freight and passenger turnover of road transportation of 31 provinces in China during 32 years (from 1981 to 2012) is collected. Meanwhile, to simplify the research, the passenger turnover of road, railway, airway, and waterway is transferred to freight turnover according to the general standards to reduce the unknown scalars.

4.1.2. $\mathrm{GDP}_{i}$ and People and RC (Route Coverage). Freight and passenger turnover is related to economic level, industry structure, and population in each province. In theory, the higher the level of economic development, the more population, and the more route coverage there is, the more transportation turnover there is. For the factor of industrial structure, the tertiary industry (service) impacts the transport turnover less than the first and the secondary industries. This paper chose GDP with different industries to be the measurement of local economic level and industry structure. The GDP of the primary, secondary, and tertiary industry and population of each province are collected to be exogenous explanatory variables in spatial econometric model.

4.2. Spatial Correlation Analysis. Before setting up the model, this paper tested the global spatial correlation of freight and passenger turnover of road firstly. The data of road turnover 


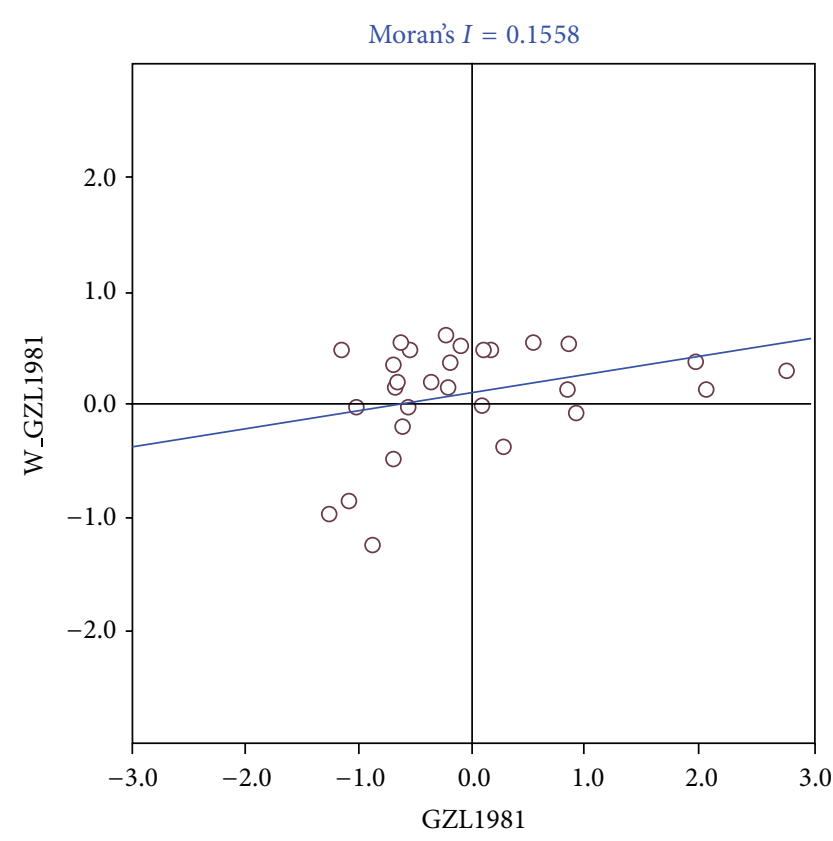

(a) Moran's I of road turnover in 1981

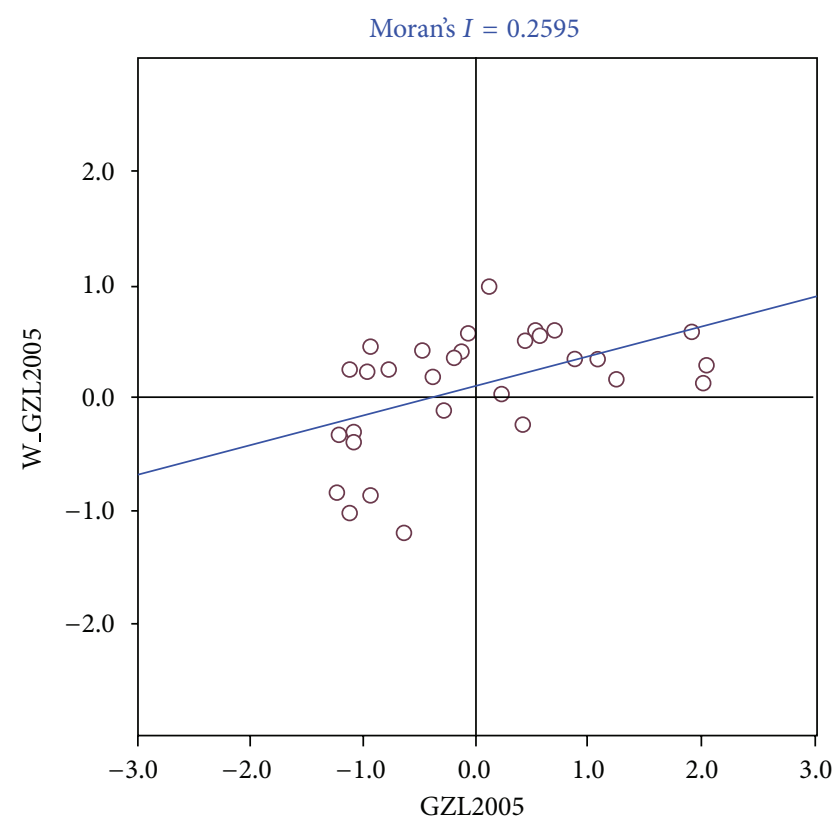

(c) Moran's I of road turnover in 2005

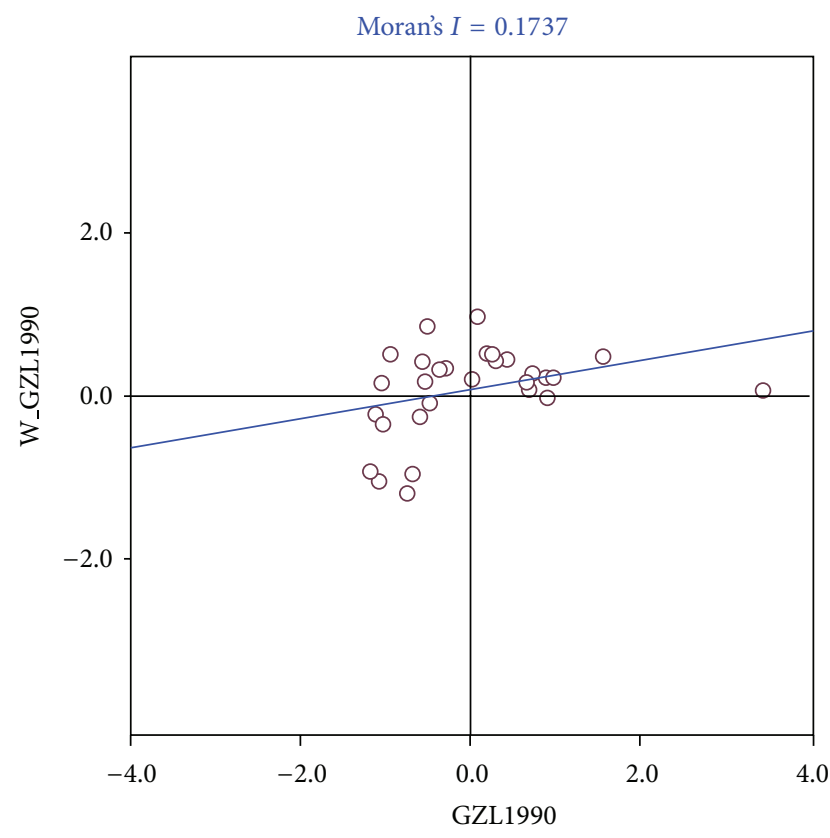

(b) Moran's $I$ of road turnover in 1990

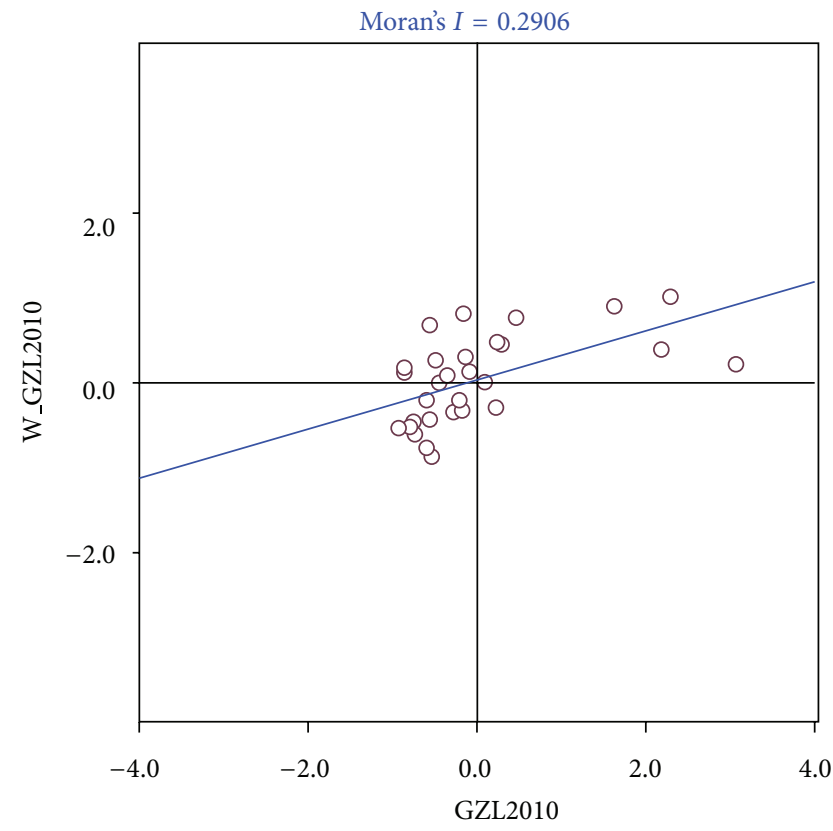

(d) Moran's I of road turnover in 2010

FIGURE 1: Moran's I of road turnover.

(freight and passenger) of 31 provinces from 1981 to 2012, a total 32 years, is adopted. Software package GeoDA is used to calculate Moran's $I$ index. The result is shown in Figure 1.

Figure 2 shows that although the spatial correlation of road turnover (freight and passenger) fluctuates, the trend has been rising since 1981 on the whole. The initial figure is 0.1558 and increases to 0.2985 by 2012 . The growth indicates that, with economic progress, road transportation system has developed rapidly. The relationship among provinces has become closer, and the degree of spatial dependence of road turnover (freight and passenger) among regions has been greater. The analysis of global spatial correlation in this section shows that whatever the space matrix is, the freight and passenger turnover of road between regions has strong spatial correlation. Thus, the influencing factors of space should be taken into consideration in the analysis.

In order to clear the influence of time and space on space correlation of the road turnover, it is necessary to perform 


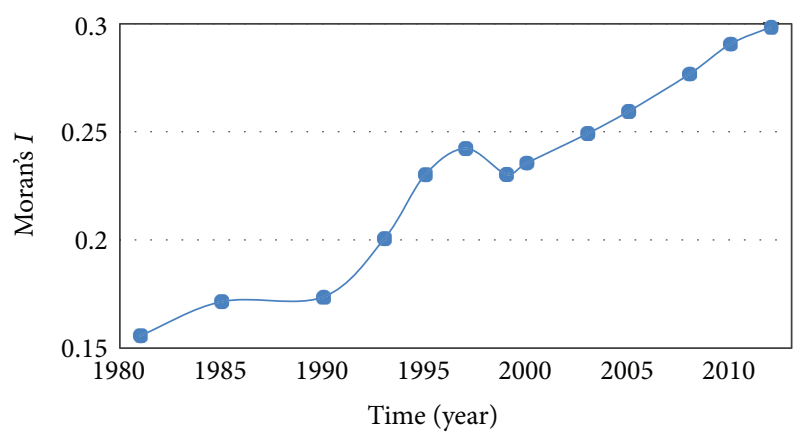

Figure 2: Tendency of Moran's $I$ of road turnover (freight and passenger) during 32 years.

a further study. This paper calculates the Moran's I of road turnover (freight and passenger) under different Euclidean distance in 2004 and 2012. The results are shown in Figure 3.

It can be seen from Figure 3 that the space correlation of road turnover among 31 provinces decreased with the increasing of Euclidean distance. With the distance below $15 \mathrm{~km}$, the space correlation in 2012 is greater than that in 2004 . But when the distance is more than $15 \mathrm{~km}$, the space correlation in 2012 is weaker. It can be inferred that for the short-haul transportation, the space correlation of road turnover (freight and passenger) increased with the development of network and road infrastructure in the past 6 years. With the development of social economy and the process of location, many companies think more about local ingredients and reducing the long-haul transport, in order to reduce the transportation costs. So, for long-haul transportation, the space correlation debased.

4.3. Local Indicators of Spatial Association. Local indicators of spatial association (LISA analysis) is used to further study the spatial structure and cluster phenomenon of provincial road turnover (freight and passenger) as a supplement for global space correlation. The spatial matrix adopted is distance weight with the Euclidean distance of $1016.6 \mathrm{~km}$. The result is shown in Figure 4.

As is seen visually from the figure, red areas represent regions with larger road turnover (freight and passenger); meanwhile the volumes in their surrounding regions are also high. These areas are Liaoning, Jiangsu, Shanghai, Zhejiang, and Jiangxi. Blue areas represent regions with smaller turnover of road, and the volumes in their surrounding regions are also low. These areas are Xinjiang, Gansu, Qinghai, and Sichuan. Light blue areas are regions of low turnover volume but with high volume in the adjacent areas. This is a negatively related relationship, and the areas are Anhui and Tianjin. The correlations of road turnover (freight and passenger) studied in this paper are mostly positive and only a few areas are negative.

Factors such as economy, industrial structure, and geographical conditions in each province are different, so is the transport structure. In order to reach the goal of energy conservation and emissions reduction, it is hard to adjust 31 provinces at the same time when the authorities take

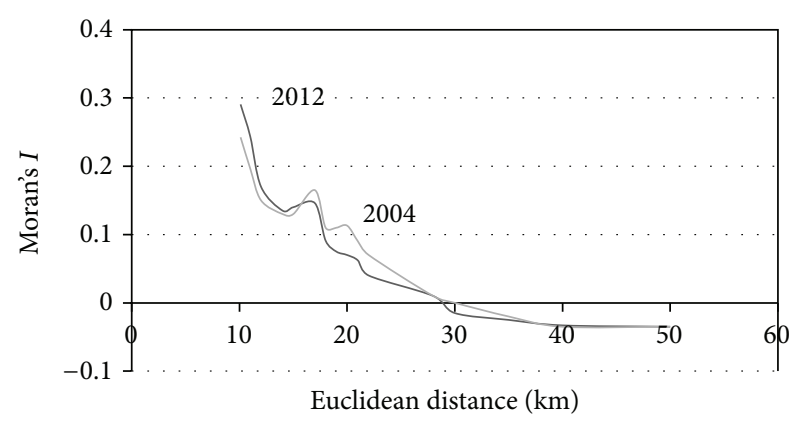

FIgURE 3: The space correlation of road turnover under different Euclidean distance.

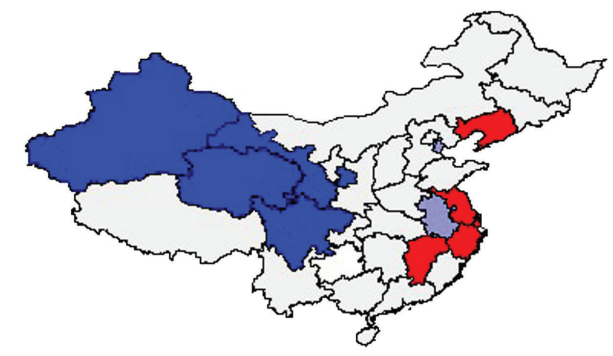

LISA cluster map:

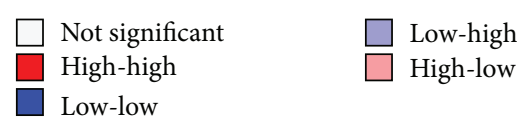

Figure 4: Local Indicators of spatial association.

measure to transfer the enterprise and resident performances of choosing transport modes. Thus, provinces that can be performed best should be selected through analysis so as to achieve the goal of maximum output with minimum input. The changes of turnover volume in one or more provinces would result in the corresponding change in its surrounding provinces. Highway transportation is usually transferred to waterway, while the integrated transport system structure is optimized. Thus, the regions with developed waterway and stronger spatial correlation should be considered for the macroeconomic regulation and control in order to reduce the proportion of road turnover, such as Liaoning, Jiangsu, Shanghai, and Zhejiang.

4.4. Spatial Relation Model. Based on the data of 2012, this part is mainly to set up two space models: spatial lag model (SLM) and spatial error correction model (SEM). Here we choose the Euclidean distance among each province (municipalities and autonomous regions) as spatial weight. Through the comparative analysis of above models, the space effects of road turnover (freight and passenger) and the influencing modes will be revealed. It is possible to provide reference for energy conservation and emission reduction.

As a whole, the amount of a region's freight and passenger turnover is the result of the comprehensive function of many factors. Since we could not describe all the relevant factors in detail, we only chose some representatives. (1) Economic 
level: generally, the more developed a region's economy is, the more developed the transportation system is, and the more freight and passenger turnover is produced. (2) Industrial structure: the contribution of primary industry to cargo turnover is larger, while that of tertiary industry is small. (3) Population: without considering other factors, greater population means higher passenger traveling intensity. (4) Route coverage: the spatial lag model to examine provincial road transport volume is as follows:

$$
\begin{aligned}
\mathrm{RT}_{i}= & \rho \mathbf{W} \times \mathrm{RT}_{i}+\alpha_{i}+\beta_{1} \mathrm{FGDP}_{i}+\beta_{2} \mathrm{SGDP}_{i} \\
& +\beta_{3} \mathrm{TGDP}_{i}+\beta_{4} \text { People }_{i}+\beta_{5} \mathrm{RC}_{i}+\varepsilon_{i} .
\end{aligned}
$$

In formula (6), index $i$ is for province. $\mathbf{W}$ is a spatial weight matrix of $31 * 31 . \mathbf{W}_{i j}$ in $\mathbf{W}$ defines the spatial relationship which is known as Distance Weight. $\mathbf{W} \times \mathrm{RT}_{i}$ is dependent variable of spatial lag. $\rho$ is the coefficient of spatial autoregressive, and its estimated value reflects the direction and size of the spatial correlation. $\beta_{x}(x=1,2,3,4,5)$ is variable coefficient. $a_{i}$ and $\varepsilon_{i}$ represent the constant and the random error, respectively.

When the spatial correlation is transmitted through the variable ignored by explanatory variables of the model, it is assumed to be produced by error process. Space error model of road turnover (freight and passenger) is as follows:

$$
\begin{aligned}
\mathrm{RT}_{i}= & \alpha_{i}+\beta_{1} \mathrm{FGDP}_{i}+\beta_{2} \mathrm{SGDP}_{i}+\beta_{3} \mathrm{TGDP}_{i} \\
& +\beta_{4} \text { People }_{i}+\beta_{5} \mathrm{RC}_{i} \lambda \times \mathbf{W} \varepsilon_{i j}+\mu_{i} .
\end{aligned}
$$

In Formula (7), $a_{i}$ is the intercept term. $\mathbf{W} \varepsilon_{i j}$ is the space lag error. $\lambda$ is the spatial error autocorrelation coefficient which indicates the spatial correlation intensity between regression residuals. $\beta_{x}(x=1,2,3,4,5)$ is the variable coefficient and $\mu_{i}$ represents the random error term.

FGDP means GDP of the first industry, SGDP means GDP of the second industry, and TGDP is GDP of the third. These three indexes indicate both the economic level and industrial structure. People is the total population in the region and $\mathrm{RC}$ is route coverage.

According to the data 2012, the above two spatial models and a conventional model (i.e., does not consider the spatial correlation) are used to study the relevance, and the results are shown in Table 1.

As is seen from the regression results, $R$-squared is greater than 0.8 in the three models and in SAM is the largest, nearly 0.9. Besides, the spatial regression for $R$-squared is superior to the traditional result. Under SLM model, the spatial autoregressive coefficient is 0.5578 which indicates that for a certain province, if the road turnover (freight and passenger) drops 1 unit in its adjacent province within $1016.6 \mathrm{~km}$, it would decrease 0.5578 units. This is a strong correlation, while under SEM, spatial error autocorrelation coefficient is 0.597 . It means that regional correlation impacted by unobserved factors in each province also plays a positive role in the road turnover.

The results also yield that the contribution of the primary and secondary industry to the turnover of road is greater than the tertiary industry. The government making efforts to
TABLE 1: Road turnover regression results.

\begin{tabular}{lccc}
\hline Model variable & Tradition & SAM & SEM \\
\hline$R$-squared & 0.845 & 0.894 & 0.853 \\
FGDP & 2.0867 & 1.8101 & 1.676 \\
SGDP & 0.205 & 0.1879 & 0.1738 \\
TGDP & 0.043 & 0.0015 & 0.0144 \\
People & -0.933 & -0.775 & -0.716 \\
RC & 1.7904 & 1.3490 & 0.9962 \\
$\alpha$ & 992.135 & 212.91 & 1044.04 \\
$\rho$ & & 0.5578 & \\
$\gamma$ & & & 0.597 \\
\hline
\end{tabular}

optimize the industrial structure and increase the proportion of service industry is conducive to reducing turnover. And further, transport energy consumption could be reduced and the goal of energy conservation and emissions reduction would be also achieved.

\section{Scenario Analysis}

In this section, three scenarios are established according to different economic growth and degree of emission reduction to analyze the influence of the reduction of road turnover in regions with high spatial cluster effect to the whole country. We carry on a comparative analysis for the different states under each scenario and come up with how to use the space effect of road turnover to energy saving and emission reduction in transportation industry.

5.1. Scenarios and Hypothesis. As mentioned above, road turnover has relations with economic level, industrial structure, and population. At the same time, road turnover has spatial correlation. This paper sets three scenarios for economic development level in the future. According to the spatial relation model, the road turnover in 2013 under different scenarios can be calculated. On the basis of feasibility and regression fitting, the spatial lag model is chosen to calculate. Liaoning, Shanghai, Jiangsu, and Zhejiang are coastal regions; in each scenario, the authorities exert political pressure to the four regions and water transportation is developed rapidly. Jiangxi province is an inland area, so railway transportation is developed mainly. Therefore, the quantity of road turnover is reduced. Since the five regions are areas with high spatial cluster effect, the reduction of the road turnover in these areas will make the road turnover in the surrounding areas reduce. Then, we can get the percentage decline of road turnover in the whole country and observe the interaction effect of road turnover's spatial correlation.

In our model, with the availability of partial data and the feasibility of calculation with spatial lag model, the following assumptions are conducted for the model.

(1) When the road turnover is computed, only the economic level, industrial structure, and population are considered. 
TABLE 2: Scenarios of economic growth and degree of emission reduction.

\begin{tabular}{lll}
\hline Scenarios & Introduction & Related parameters \\
\hline \multirow{3}{*}{ High-growth scenario } & $\begin{array}{l}\text { The domestic economic development is good and the authorities of China adopt a } \\
\text { high degree of macrocontrol. The road turnover of the five regions mentioned above } \\
\text { transferred to waterway and railway largely. The philosophy of low-carbon is deep } \\
\text { in the human mind and the implementation environment of low-carbon is fine. }\end{array}$ & $\begin{array}{l}\text { GDP growth rate: } \\
10 \% . \\
\text { The reduction rate of } \\
\text { road turnover: } 25 \%\end{array}$ \\
\hline \multirow{3}{*}{ Moderate-growth scenario } & $\begin{array}{l}\text { The domestic economic development is stable and the road turnover grows steadily. } \\
\text { The authorities introduce relatively soft macro-control policies. }\end{array}$ & $\begin{array}{l}\text { GDP growth rate: } 8 \% . \\
\text { The reduction rate of } \\
\text { road turnover: } 15 \%\end{array}$ \\
\hline \multirow{2}{*}{ Low-growth scenario } & $\begin{array}{l}\text { A variety of uncertainties in the future are taken into account, so the domestic } \\
\text { economic development is poor. In this economic environment, the increase in road } \\
\text { turnover is small, and the measures adopted by authorities are slight. }\end{array}$ & $\begin{array}{l}\text { GDP growth rate: } 6 \% . \\
\text { The reduction rate of } \\
\text { road turnover: } 5 \%\end{array}$ \\
\hline
\end{tabular}

(2) When we use the spatial lag model to compute the road turnover, if the turnover in the right and left of the equation is of the same period, the calculation is infeasible. Thus, this paper let the road turnover in the right of the equation release in time. It is assumed that the turnover in the left of the equation has the same spatial correlation with the date in the right of last period.

(3) The industrial structure does not change in the future.

The economic development level and degree of emission reduction are considered comprehensively to establish the scenarios. The scenarios are as follows: high-growth scenario, moderate-growth scenario, and low-growth scenario. The GDP growth rate of China during 1987 and 2012 is 8 12\% and fluctuates up and down with the center of $10 \%$. But the economics of domestic and overseas are both in depression, so the data of economic growth is set as follows. The details of each scenario are shown in Table 2.

5.2. Scenario Analysis. This paper lets the road turnover in the right of the equation of the Spatial Lag Model release in time with the data of road turnover in 2012. The data of GDP and population is in 2013. By the model, the road turnover of each province in 2013 can be calculated. According to polices and projections of Five-Year Plan (2011-2015) drafted by the provincial population and family planning commission, we collected the data of population in 2013. Under the three scenarios, the road turnover in Liaoning, Shanghai, Jiangsu, Zhejiang, and Jiangxi in 2012 is reduced by 25\%, 15\%, and $5 \%$. With the Spatial Lag Model, the road turnover of other regions and the whole country in 2013 can be calculated again. The data before and after reduction are compared. We observe the reduction rate of road turnover in the regions that have spatial correlation with the five areas and the reduction rate in China. The lessening of the road turnover will carry out the reduction of energy consumption and carbon dioxide emissions. The results are shown as Figure 5.

It can be seen from Figure 5 that, in each scenario, the reduction of road turnover in the five regions (Liaoning, Jiangsu, Shanghai, Zhejiang, and Jiangxi) drives the road turnover of their adjacent areas decreasing at the same time. But the degrees of reduction in each region are different. Because for a province, apart from its adjacent areas, the quantity of its road turnover is also related with the economic level, industrial structure, and population of its own region. When the reduction rates of road turnover in the five regions are $25 \%, 15 \%$, and $5 \%$, respectively, the reduction rates in China are $6.4 \%, 3.3 \%$, and $1.3 \%$. Although the reduction rates in the whole country are less than the rates in the five regions, these are the achievements with the control of only certain areas. It is significant to reduce the carbon emissions all over the country through the emission reduction in part provinces.

Under the high-growth scenario, the road turnover increases rapidly with the quick development of the economy. Meanwhile, the degree of emission reduction is great. The reduction rates of road turnover in the regions with high spatial cluster effect are high, and the rates in their adjacent areas are relatively large. The reduction of the road turnover in the whole country is significant. Under the scenario of moderate-growth, the reduction rate of China is $3.3 \%$. The number may seem to be unobvious, but it is the achievement of one year. If the authorities take measures of macrocontrol to partial regions every year, the road turnover will decrease year by year. When the quantity of road turnover in each province is changed, the local indicators of spatial association is used again to choice the appropriate areas, and the authorities take macroeconomic control to these new areas. The cumulative effect of road turnover reduction is considerable. Furthermore, these stable economic growth and gentle emission reduction efforts are suitable for the current economic development situation. In the low-growth scenario, the economic growth is slow, and the degree of emission reduction is low. Without taking other saving measures, the percentage of the total reduction in China is low, and the effect of emission reduction is unobvious. For the above three scenarios, the moderate-growth scenario is more coincident with the situation of China. On the basis of stable economic development, the degree of energy saving and emission reduction is gentle.

\section{Conclusion and Prospect}

In the era context of energy saving and emission reducing, transportation industry, a high energy consumption industry, should take measures actively to reduce carbon emissions. The quantities of carbon emission in transportation industry are directly related with transport turnover of comprehensive transportation system, so it is important to study the 


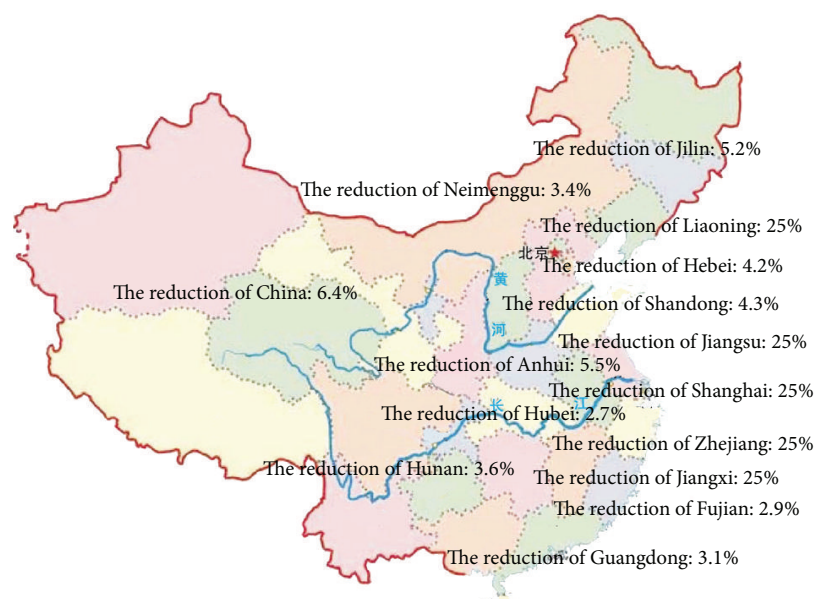

(a) The reduction of road turnover under high-growth scenario

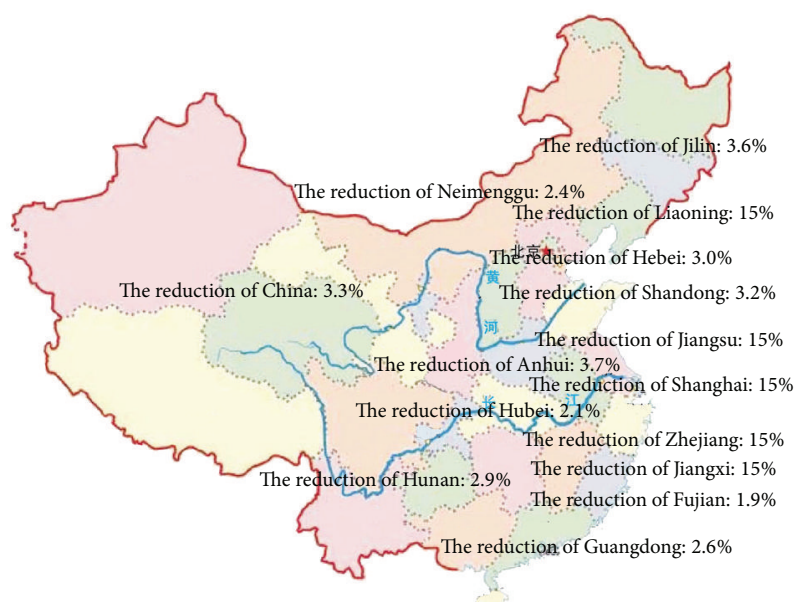

(b) The reduction of road turnover under moderate-growth scenario

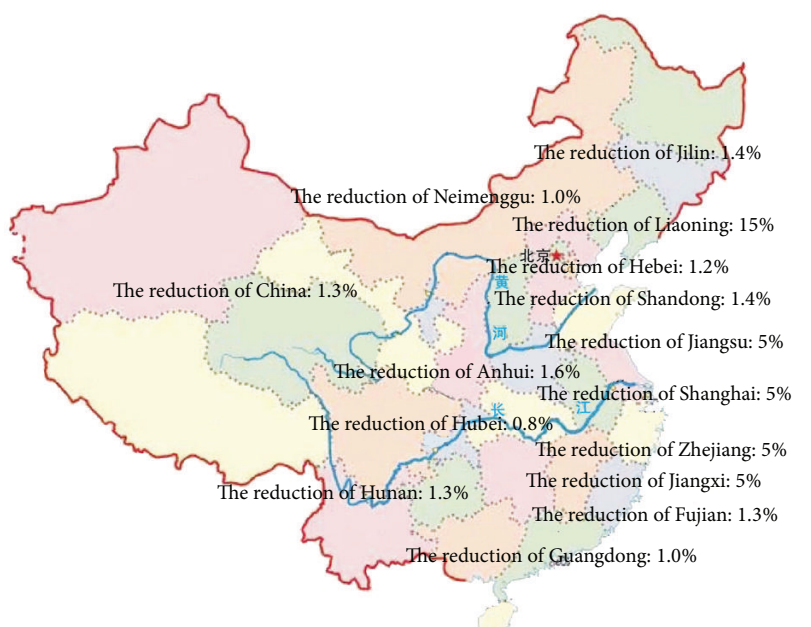

(c) The reduction of road turnover under low-growth scenario

Figure 5: The reduction of road turnover.

characteristics of transport turnover. By the global spatial correlation, it can be found that road turnover (freight and passenger) has strong spatial correlation, and with the increasing of turnover the trend is rising year by year. Meanwhile, the examination with the local spatial correlation in each province shows that Liaoning, Jiangsu, Shanghai, Zhejiang, and Jiangxi have high spatial cluster effects in transport turnover. The spatial correlation should be considered when authorities take macroeconomic regulation and control to reduce the road turnover. However, macroeconomic regulation and control is difficult to be carried out nationally at the same time. Thus, this paper suggests to control the above five areas, making them drive the surrounding provinces and cities simultaneously.

Road turnover in certain region is positively related with its economic level, population, and transport volumes of surrounding areas. The spatial correlation is obvious. Meanwhile, the industrial structure also affects the volume of the turnover, and the influence of the primary and secondary industry to the road turnover (freight and passenger) is greater than the tertiary industry. The government making efforts to optimize the industrial structure and increase the proportion of service industry is conducive to reducing turnover. Through the scenario analysis, we find that with the reduction of road turnover in Liaoning, Jiangsu, Shanghai, Zhejiang, and Jiangxi, the turnover of their adjacent areas is also reduced. The moderate-growth scenario is more coincident with the situation of China. On the basis of stable economic development, the degree of energy saving and emission reduction is gentle. It can be seen that taking the space correlation of turnover into consideration for energy saving and emission reduction in transportation industry is an efficient way.

\section{Acknowledgments}

This work was supported by The National Natural Science Foundation of China (nos. 51078049 and 51108053), Humanities and Social Sciences Foundation from the Ministry of Education of China (09YJA790021), the Trans-Century 
Training Program Foundation for Talents from the Ministry of Education of China (NCET-12-0752), and Liaoning Excellent Talents in University (LJQ2012045).

\section{References}

[1] “The United Nations Climate Change conference," Copenhagen, Danish, 2009.

[2] B. Z. Yao, P. Hu, M. H. Zhang, and S. Wang, "Artificial bee colony algorithm with scanning strategy for the periodic vehicle routing problem," Simulation, vol. 89, no. 6, pp. 762-770, 2013.

[3] B. Yu and Z. Z. Yang, "An ant colony optimization model: the period vehicle routing problem with time windows," Transportation Research E, vol. 47, no. 2, pp. 166-181, 2011.

[4] B. Yu, Z. Z. Yang, and L. I. Shan, "Real-time partway deadheading strategy based on transit service reliability assessment," Transportation Research A, vol. 46, no. 8, pp. 1265-1279, 2012.

[5] B. Yu, H. B. Zhu, W. J. Cai, N. Ma, and B. Z. Yao, "Twophase optimization approach to transit hub location-the case of Dalian," Journal of Transport Geography, vol. 33, pp. 62-71, 2013.

[6] R. Saidur, M. A. Sattar, H. H. Masjuki, S. Ahmed, and U. Hashim, "An estimation of the energy and exergy efficiencies for the energy resources consumption in the transportation sector in Malaysia," Energy Policy, vol. 35, no. 8, pp. 4018-4026, 2007.

[7] S. Jeffrey and W. Yanjia, "China on the move: oil price explosion?” Energy Policy, vol. 35, no. 1, pp. 678-691, 2007.

[8] A. A. Amekudzi, C. Jotin Khisty, and M. Khayesi, "Using the sustainability footprint model to assess development impacts of transportation systems," Transportation Research A, vol. 43, no. 4, pp. 339-348, 2009.

[9] L. Anselin, "Spatial econometrics," A working paper, Center for Spatially Integrated Social Science, 1999.

[10] L. Anselin, "Spatial econometrics in RSUE: retrospect and prospect," Regional Science and Urban Economics, vol. 37, no. 4, pp. 450-456, 2007.

[11] S. J. Rey and B. D. Montouri, "US regional income convergence: a spatial econometric perspective," Regional Studies, vol. 33, no. 2, pp. 143-156, 1999.

[12] D. M. Brasington and D. Hite, "Demand for environmental quality: a spatial hedonic analysis," Regional Science and Urban Economics, vol. 35, no. 1, pp. 57-82, 2005.

[13] L. Anselin, Spatial Econometrics: Methods and Models, Kluwer Academic Publishers, Dordrecht, The Netherlands, 1988.

[14] J. P. Elhorst, "Specification and estimation of spatial panel data models," International Regional Sciences Review, vol. 26, no. 3, pp. 244-268, 2003.

[15] B. H. Baltagi, P. Egger, and M. Pfaffermayr, "Estimating models of complex FDI: are there third-country effects?" Journal of Econometrics, vol. 140, pp. 260-281, 2007.

[16] M. Kapoor, H. H. Kelejian, and I. R. Prucha, "Panel data model with spatially correlated error components," Journal of Econometrics, vol. 140, no. 1, pp. 97-130, 2007.

[17] H. H. Kelejian and I. R. Prucha, "A generalized moments estimator for the autoregressive parameter in a spatial model," International Economic Review, vol. 40, no. 2, pp. 509-533, 1999.

[18] B. Z. Yao, C. Y. Yang, and J. B. Yao, “Tunnel surrounding rock displacement prediction using support vector machine," International Journal of Computational Intelligence Systems, vol. 3, no. 6, pp. 843-852, 2010. 


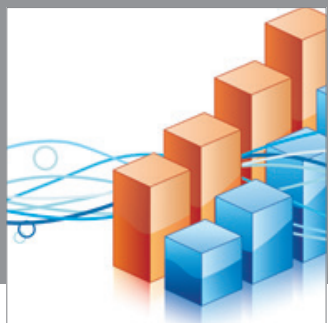

Advances in

Operations Research

mansans

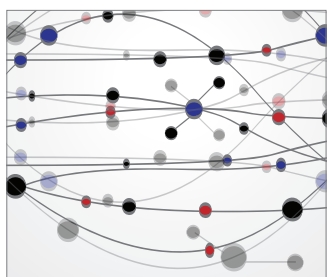

The Scientific World Journal
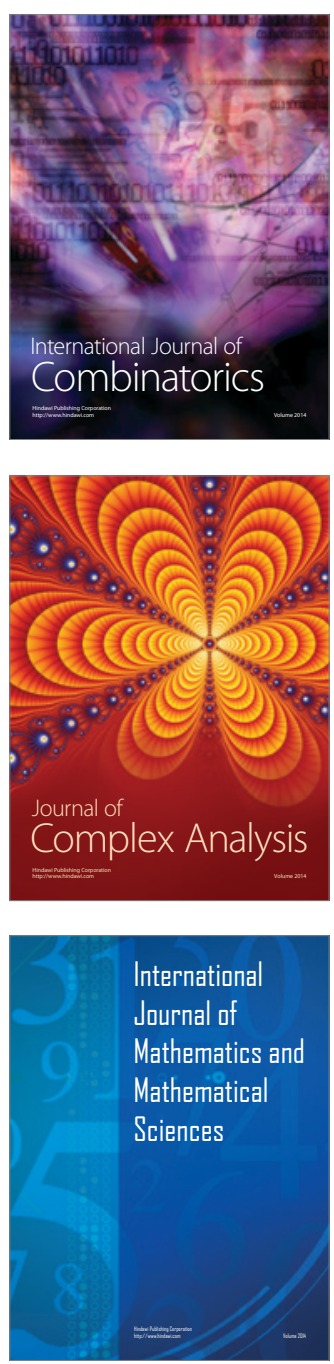
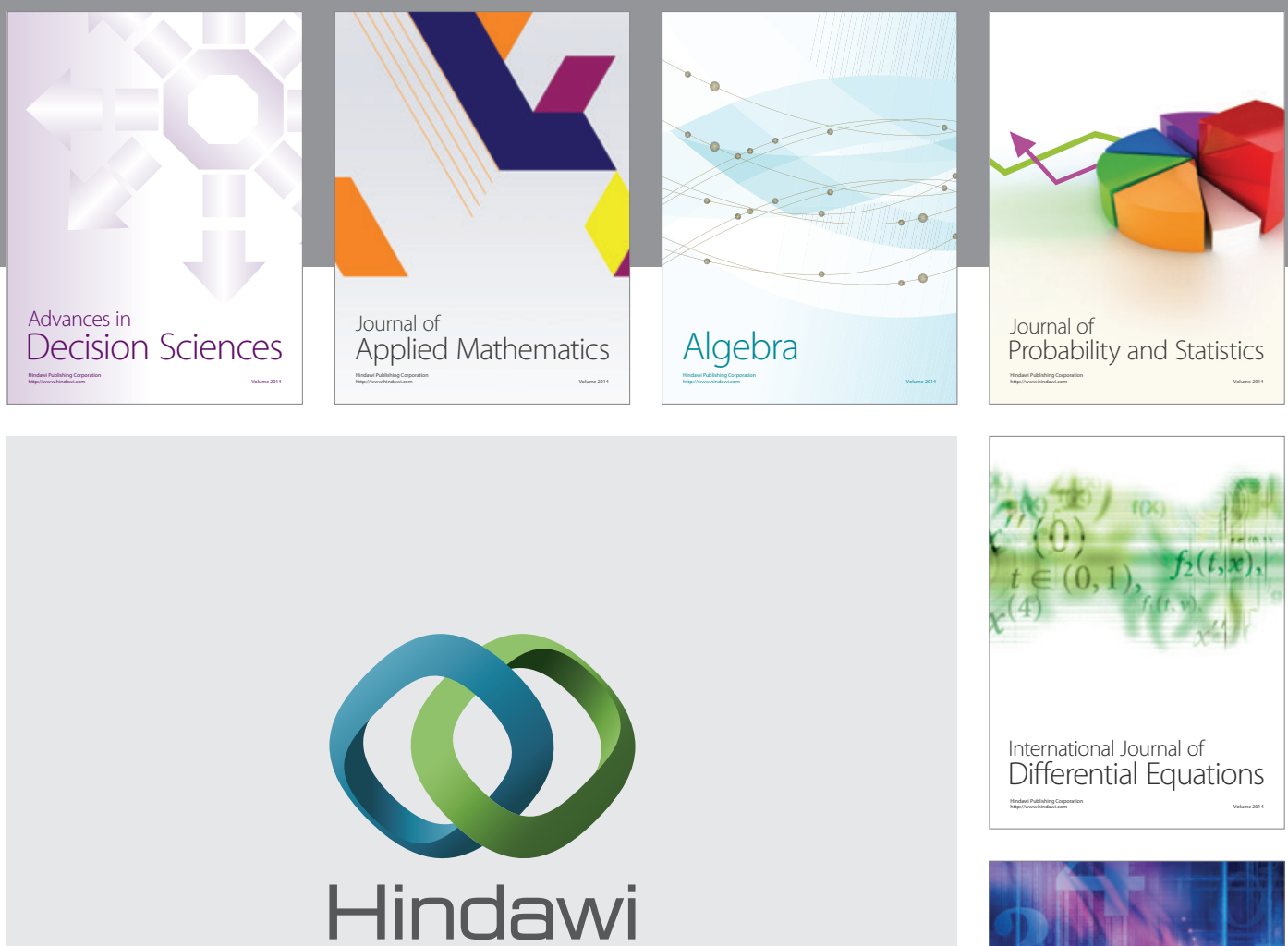

Submit your manuscripts at http://www.hindawi.com
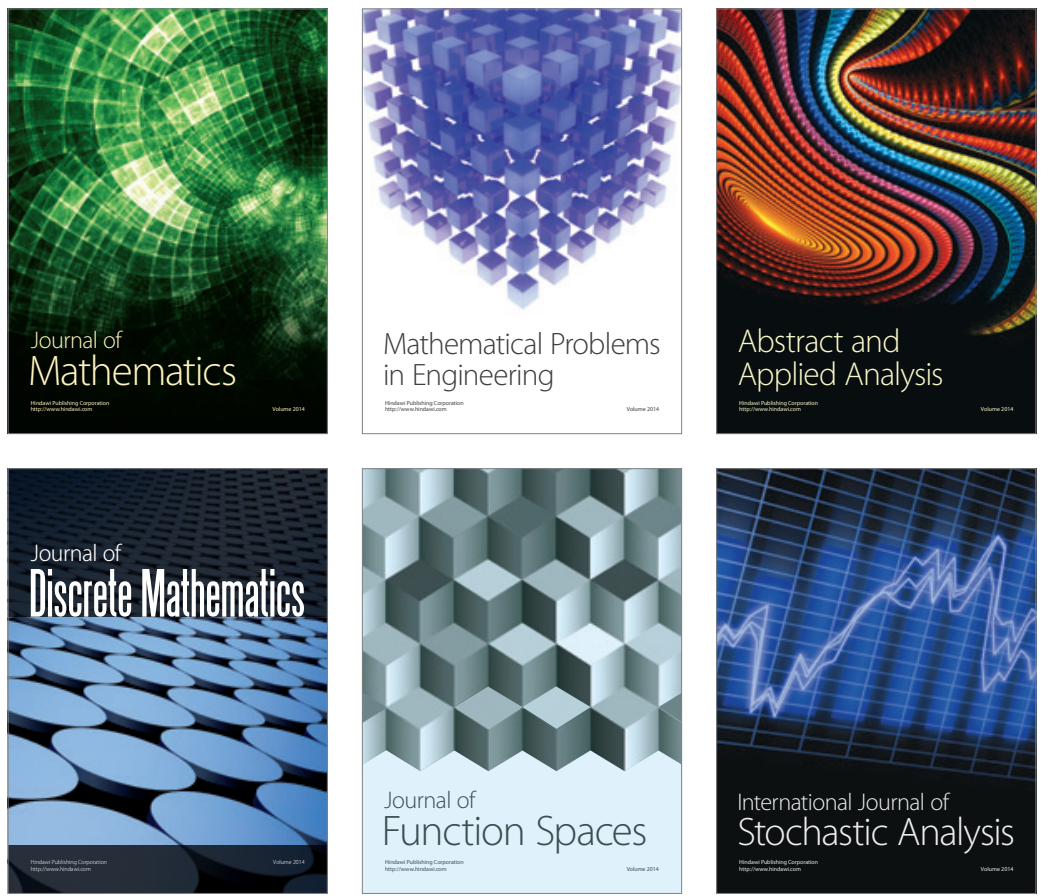

Journal of

Function Spaces

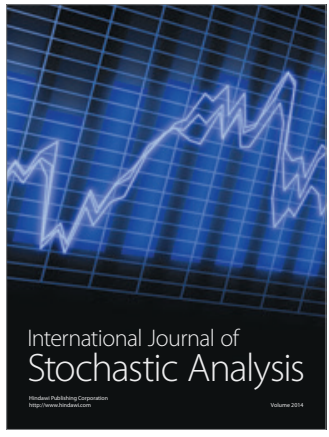

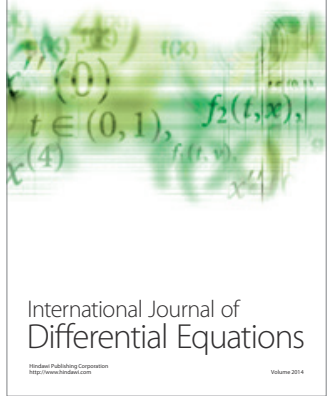
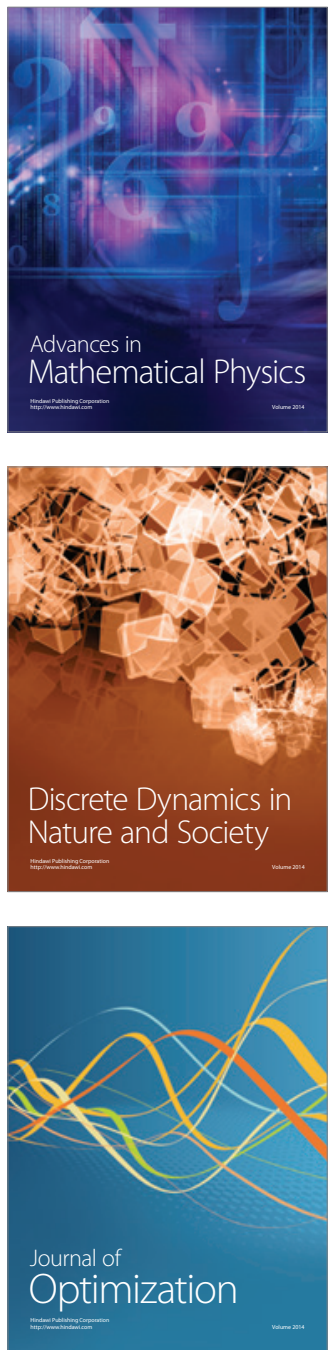